\title{
Influence of substrate hydrophobicity on the adsorption of an amphiphilic diblock copolymer
}

\author{
De Cupere V.M. ${ }^{[1]}$, Gohy J.-F[2], Jérôme R${ }^{[2]}$, Rouxhet P.G ${ }^{[1]}$ \\ [1] Unité de Chimie des Interfaces, Université Catholique de Louvain, Croix du Sud, 2/18, 1348 \\ Louvain-la-Neuve, Belgium \\ ${ }^{[2]}$ Centre for Education and Research on Macromolecules, Université de Liège, Sart-Tilman B6, 4000 \\ Liège, Belgium
}

\begin{abstract}
The adsotption of poly(tert-huty]methacrylate)-block-poly(2-(dimethylamino-ethyl) mefhacrylate) (PtBUMA-b-PDMAEMA) was studied by X-ray photoelectron spectroscopy (XPS) and atomic force microscopy (AFM) analysis performed on dried samples. The copolymer was dissolved in toluene at concentrations below $(0,01 \mathrm{wt} \%)$ and above $(0.05$ and $1 \mathrm{wt} \%)$ the $\mathrm{CMC}$; silicon $(\mathrm{SiOH})$ and $\mathrm{CH} 3$ grafted silicon $\left(\mathrm{SiCH}_{3}\right)$ were used as substrates Whatever the concentration and the substrate, a layer of individual copolymer molecules, $1.5-3 \mathrm{~nm}$ thick, formed rapidly The adsorbed amount was slightly higher and the resistance to AFM tip scraping was stronger on $\mathrm{SiOH}$ than on $\mathrm{SiCH}_{3}$ This is attributed to hydrogen bonding between the PDMAEMA block and the $\mathrm{OH}$ groups of the silicon surface, leading to polarization of the adsorbed layer: Above the $\mathrm{CMC}$, on $\mathrm{SiOH}$, randomly scattered dot-like features (about $5 \mathrm{~nm}$ high) observed by AFM were attributed to individual micelles, which were not displaced by drying. On $\mathrm{SiCH}_{3}$, the particles found on the top of the adsorbed layer were micelle aggregates, about $50 \mathrm{~nm}$ thick, the lateral size of which was strongly influenced by the rate of drying. This further difference between $\mathrm{SiCH}_{3}$ and $\mathrm{SiOH}$ is tentatively attributed to the exposure of PDMAEMA by the adsorbed layer formed on $\mathrm{SiCH}_{3}$, while only PtBUMA would be exposed by the layer adsorbed on $\mathrm{SiOH}$ The red blood cell shape and the size of the micelles observed in single layers indicate that the PtBUMA corona was not made compact as a result of drying.
\end{abstract}

\section{Keywords}

Adsorption; Amphiphilic copolymer; Hydrophobicity; Poly(tert-butylmethaciylate); Poly(2(dimethylaminoethyl) methaciylate); Silicon; Grafting; Polymer micelles; AFM; XPS

\section{Introduction}

Adsorption of copolymer micelles onto different substrates has been of growing interest in the past 10 yr. PEO-containing micelles were adsorbed from aqueous solutions and, in some cases, covalently bound to the surface of bio-materials in order to avoid protein adsorption and/or to play the role of drug carrier [1-3]. Etching one of the components in a monolayer of adsorbed micelles is an easy way to obtain a nanolithographic mask [4] Micelles, adsorbed or not, can be used as nanoreactors for the production of other nanoparticles, for example of gold colloids [5]; cross-linking the shell and etching the core forms nanocages able to encapsulate large quantities of guest molecules [3] Adsorption of copolymers is a complex process Solutions from which the adsorption proceeds may contain only individual macromolecules (below the CMC) or individual and aggregated species of different shapes and properties (above the CMC), depending on the solvent [6] Each of these entities possesses its own affinity for the surface, defined by its intrinsic properties but also by the chemical and physical properties of the surface [7-9] Adsorption of copolymers, even below the CMC, may lead to the formation of an adsorbed micelle layer, since the presence of the solid surface can induce association of adsorbed species [6,10] One must also keep in mind that surface reorganization may occur upon drying [11]; this is taken into account by few authors [12].

In this paper, we report on the adsorption of an amphiphilic diblock copolymer, poly(tert-butylmethacrylate)-block-poly(2-(dimethylamino-ethyl)methacrylate) (PtBUMA- $b$-PDMAEMA) Concentrations 
below and above the critical micelle concentration (CMC) were investigated and the adsorption was performed on a hydrophilic (silicon) and on a hydrophobic substrate (silanized silicon). Two methods of drying were also tested. Atomic force microscopy (AFM) allowed the morphology of the adsorbed layer to be described while estimation of the adsorbed amount was performed by X-ray photoelectron spectroscopy (XPS).

\section{Materials and methods}

\subsection{Substrates}

Silicon was provided as 5-cm-diameter wafers with a thickness of $1 \mathrm{~mm}$ (Siltronix, France) It was cleaned by immersion for half an hour in $100 \mathrm{ml}$ of piranha solution $\left(10 \mathrm{H}_{2} \mathrm{SO}_{4}: 1 \mathrm{H}_{2} \mathrm{O}_{2}\right.$, v:v), followed by 10 successive rinsings with $100 \mathrm{ml}$ of Milli-Q water (HPLC grade produced by a Milli-Q Plus system from Millipore, Mosheim, France). Sulfuric acid 95-98\% $\left(\mathrm{H}_{2} \mathrm{SO}_{4}\right)$ and hydrogen peroxide 30 wt $\%$ solution in water $\left(\mathrm{H}_{2} \mathrm{O}_{2}\right)$ were Aldrich products (Bornem, Belgium). The silicon was then dried with a nitrogen flow and kept in a petri dish sealed with Parafilm.. This will be referred to as $\mathrm{SiOH}$ The silanization was performed under argon in glassware previously treated with large volumes of chlorotrimethylsi-lane in order to saturate the glass walls. The cleaned wafer was introduced into $90 \mathrm{ml}$ toluene and the system was brought to $40{ }^{\circ} \mathrm{C}$ One milliliter of triethylamine (99 5\%, Ref: 47,128-3; Aldrich, Bornem) was then added in one portion, followed by $3.5 \mathrm{ml}$ of chlorotrimethylsilane (99+\%, redistilled, Ref: 38,652-9; Aldrich, Bornem) added drop by drop. The reaction was allowed to proceed for $5 \mathrm{~h}$. The wafer was then washed by successive immersions in three methanol baths and three ether baths under sonication. The grafted silicon, referred to as $\mathrm{SiCH}_{3}$, was then dried with a nitrogen flow and stored in a petri dish sealed with Parafilm

\section{2.. Achorbate}

The diblock copolymer was synthesized by living ligated anionic polymerization. Briefly, the monomers were purified by distillation over triethylaluminum. The glass reactor containing the required amount of ligand, $\mathrm{LiCl}(\mathrm{LiCl} /$ initiator molar ratio $=10 / 1)$ was flame-dried under vacuum and purged with nitrogen. The solvent (tetrahydrofuran) was then added and the system was cooled down to $-78^{\circ} \mathrm{C}$. The diphenylmethyllithium initiator was added dropwise until a persistent yellow color was observed, followed by the desired amount of monomer. tert-Butylmethacrylate was first polymerized at $-78^{\circ} \mathrm{C}$ for $1 \mathrm{~h}$, followed by DMAEMA $\left(2 \mathrm{~h}\right.$ at $\left.-78^{\circ} \mathrm{C}\right)$. A sample was collected from the reactor before the addition of DMAEMA. The copolymerization reaction was then quenched with methanol and the final product was characterized by size exclusion chromatography (SEC) and nuclear magnetic resonance (NMR). SEC was performed in THF containing $5 \mathrm{vol} \%$ of ethylamine, using a Hewlett-Packard 1050 liquid chromatograph equipped with two Plgel columns (1000 and 10,000 Á, respectively) and a Hewlett-Packard 1047A refractive index detector. Poly(methylmethacrylate) standards were used for calibration $M_{n}$ of the PDMAEMA block was calculated from the ${ }^{1} \mathrm{H}$ NMR spectrum of the copolymer' and $M_{n}$ of the Pt-BUMA block ${ }^{1} \mathrm{H}$ NMR spectra were recorded at $400 \mathrm{MHz}$ with a Biuker AM 400 spectrometer. The PtBUMA-b-PDMAEMA sample had a molar mass of 27,000 $\mathrm{g} / \mathrm{mol}$, its tBUMA block presenting a molar mass of $17,000 \mathrm{~g} / \mathrm{mol}$ The polydispersity index was 1.05 The copolymer was dissolved in toluene and the resulting solutions were analyzed by dynamic light scattering (DLS) Micelles consisting of a PDMAEMA core and a PtBUMA corona are expected to be formed in toluene. DLS measurements were performed (Brookhaven Instruments Co. BI-200 apparatus equipped with a BI-2030 digital correlator) at $480 \mathrm{~nm}$ (Ion Laser Technology argon laser) using a scattering angle of $90^{\circ}$ A refractive index matching bath of filtered water surrounded the scattering cell, and the temperature was controlled at $25^{\circ} \mathrm{C}$, The experimental intensity correlation function was measured and then analyzed using a cu-mulant expansion The mean apparent diffusion coefficient of the micelles was extrapolated to zero concentration. The hydrodynamic radius $(R h)$ was calculated using the Stokes-Einstein approximation and found to be $40 \mathrm{~nm}$ The critical micelle concentration (CMC) was determined by plotting the scattered intensity as a function of copolymer concentration (data not shown). The CMC was considered to be the concentration at which the scattered intensity started to rise markedly, which was $0.02 .5 \mathrm{wt} \%$.

The diameter of the PDMAEMA core was determined by transmission electron microscopy (TEM), using a Philips CM 100 apparatus operating at $100 \mathrm{kV}$ TEM micrographs were directly recorded with a Gatan 673 CCD camera and data were transferred to a computer equipped with the Kon-tron KS 100 software. Samples were prepared by casting one drop of the micellar solution onto a carbon-coated 
copper grid. The PDMAEMA core was selectively stained by exposure of the micelles to a diluted $\mathrm{HAuCl}_{4}$ solution The measured core diameter was about $8 \mathrm{~nm}$.

\subsection{Sample preparation}

Copolymer solutions in toluene were prepared at concentrations of 0.01 (below the CMC), 0 05, and $1.0 \mathrm{wt} \%$ (above the CMC). The substrates $\left(\mathrm{SiOH}\right.$ or $\left.\mathrm{SiCH}_{3}\right)$ were immersed in $10 \mathrm{ml}$ of polymer solution for $15 \mathrm{~min}$. Samples were then rinsed by immersing the substrates in $10 \mathrm{ml}$ toluene with gentle stirring during $10 \mathrm{~s}$; drying was performed either by evaporation of the solvent in ambient atmosphere (slow drying) or by flushing with nitrogen (fast drying). In order' to visualize micelles deposited from the solution, certain samples were prepared without rinsing and dried by flushing with nitrogen.. The samples were first observed by AFM and then analyzed by XPS.

\subsection{Analytical methods}

XPS spectra were recorded using an X-probe spectrometer (Model SSX-100/206 from Surface Science Instruments) equipped with an aluminum anode $(10 \mathrm{kV}, 12 \mathrm{~mA})$ and a quartz monochromator Charge stabilization was achieved using an electron flood gun set at $8 \mathrm{eV}$ and placing a grounded nickel grid 3 $\mathrm{mm}$ above the sample surface. The area analyzed was about $1,7 \mathrm{~mm}^{2}$. The angle between the normal to the sample surface and the direction of the pho-toelectron collection was $55^{\circ}$. With the resolution used, the full width at half maximum of the $\mathrm{AU}_{4 / 7 / 2}$ peak was about $1.0 \mathrm{eV}$. The order of peak analysis was survey scan, $\mathrm{C}_{1 \mathrm{~s}}, \mathrm{O}_{1 \mathrm{~s}}, \mathrm{~N}_{1} \mathrm{~s}$, and $\mathrm{C}_{1 \mathrm{~s}}$ again. Data treatment was performed with the ESCA 8.3D software provided by the spectrometer manufacturer, The binding energy scale was set by fixing the component due to carbon only bound to carbon and hydrogen at $284.8 \mathrm{eV}$, A Shirley background subtraction was used. Intensity ratios were converted into molar concentration ratios by using the sensitivity factors proposed by the manufacturer (mean free path varying according to the 0.7 th power of pho-toelectron kinetic energy; Scofield cross-sections; constant transmission function).

AFM analysis was performed in air at room temperature, with a commercial optical lever microscope (MultiMode Scanning Probe Microscope equipped with a Nanoscope III controller, Digital Instrument, Santa Barbara, CA) Contact mode topographic images were recorded using oxide-sharpened $\mathrm{Si}_{3} \mathrm{~N}_{4}$ miciolevers (Park Scientific Instruments, Mountain View, CA; C to E triangular cantilevers; Ref. MSCT-AUHW) with a radius of curvature of 20-60 nm and a spring constant ranging from 0.01 to 0.1 $\mathrm{N} / \mathrm{m}$ The scan rate was $2 \mathrm{~Hz}$ and the loading force was set at the minimum value allowing contact between the tip and the sample. In order to examine the resistance of the adsorbed layer to AFM tip damage and to possibly measure its thickness, the surface was scraped by performing five scans on a 2 x $2 \mu \mathrm{m}$ area at a loading force of $8 \mathrm{nN}$ and a frequency of $10 \mathrm{~Hz}$. The damage was visualized by a subsequent scan on a $10 \times 10 \mu \mathrm{m}$ area, taken at the same place with experimental setting described above.

\section{Results}

AFM images of $\mathrm{SiOH}$ and $\mathrm{SiCH}_{3}$ (images not presented) showed that both systems were very smooth and did not present any important relief features $\left(R_{r m s} \mathrm{SiOH}=0.25 \mathrm{~nm} ; R_{r m s} \operatorname{SiC} \prod 3=0.33 \mathrm{~nm}\right.$ for 5 x 5 $\mu \mathrm{m}$ images). From XPS analysis, the adventitious contamination of $\mathrm{SiOH}$ may be characterized as follows: $\mathrm{C} / \mathrm{Si}=0.35 ; \mathrm{C} /[\mathrm{C}+\mathrm{Si}+\mathrm{O}+\mathrm{N}]=0138 ; \mathrm{N} / \mathrm{Si}=0003 \mathrm{SiCH}_{3}$ gave a $\mathrm{C} / \mathrm{Si}$ ratio $=0.27$ and a $\mathrm{C} /[\mathrm{C}+\mathrm{Si}+\mathrm{O}]$ ratio $=0.116$ In the latter case, carbon may be attributed to the methyl group, as confirmed by the presence of a component at $101.5 \mathrm{eV}$ in the Si peak, due to silicon bound to carbon, which was not present on $\mathrm{SiOH}$ Comparison of carbon peaks showed similarities between $\mathrm{SiOH}$ and $\mathrm{SiCH} 3$; however, the contributions due to carbon bound to oxygen, between 286 and $290 \mathrm{eV}$, were higher on $\mathrm{SiOH}$ The water contact angles were $15^{\circ}$ for $\mathrm{SiOH}$ and $86^{\circ}$ for $\mathrm{SiCH} 3$. 


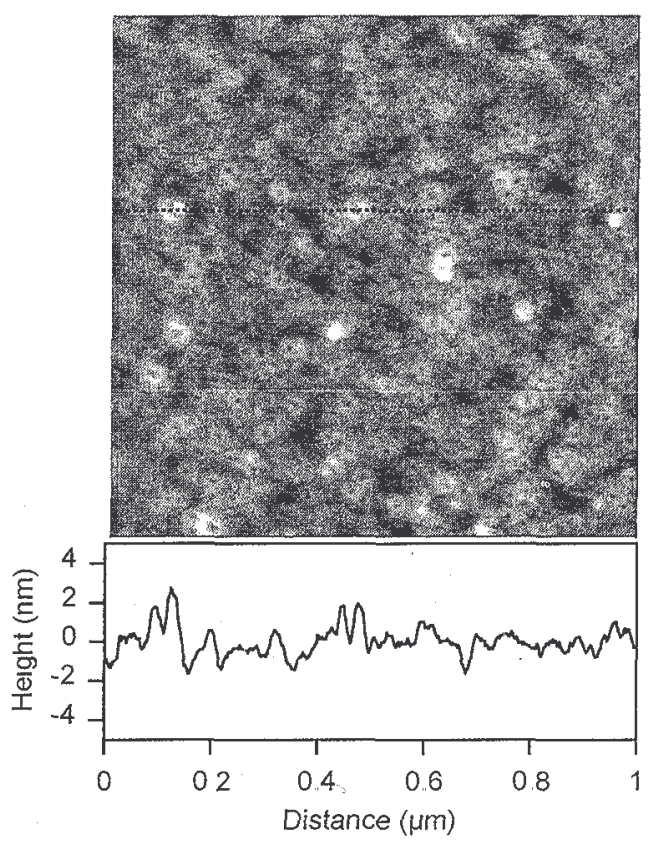

Fig $11 \times 1 \mu \mathrm{m}$ AFM image of PtBUMA-b-PDMAEMA micelles after deposition on a SiOH substratum from a $1 \mathrm{wt} \%$ solution and subsequent fast drying. Vertical scale $5 \mathrm{~nm}$. The section was taken at the place indicated by the dotted line.

The water contact angle measured on $\mathrm{SiOH}$ after XPS analysis was $45^{\circ}$. Toluene contact angles of both substrates were close to $26^{\circ}$.

The AFM image obtained after micelle deposition on $\mathrm{SiOH}$ from a $1 \mathrm{wt} \%$ solution (no rinsing) and fast drying is presented in Fig, 1, The micelles appeared with a small depression $(2 \mathrm{~nm})$ at the center (red blood cell morphology). The micelle diameter was $43 \pm 6 \mathrm{~nm}$, and the core diameter $13.0 \pm 2 \mathrm{~nm}$. The same morphology and size were observed for micelles deposited on $\mathrm{SiCH}_{3}$

AFM images of substrates after adsorption (immersion and rinsing) are presented in Figs 2 and 3. On $\mathrm{SiOH}$ at a concentration of $001 \mathrm{wt} \%$ (Figs. 2a and $2 \mathrm{~b}$ ), the background was granular and uniform (see $1 \mathrm{x} 1 \mu \mathrm{m}$ inserts); some additional dot-like features were present, with a thickness of 1-2 $\mathrm{nm}$ as seen on the section At a concentration of $1 \mathrm{wt} \%$ (Figs $2 \mathrm{c}$ and $2 \mathrm{~d}$ ) and $005 \mathrm{wt} \%$ (images not presented), the background was smooth (see $1 \times 1 \mu \mathrm{m}$ inserts) but the dotlike features had a higher density and a thickness of 2-5 nm, as seen on the sections. Whatever the concentration, the rate of drying had no influence on the morphology Scraping the samples prepared below and above the CMC displaced the dot-like features, as seen on the sections shown with the images of Figs. 4a and 4c. 


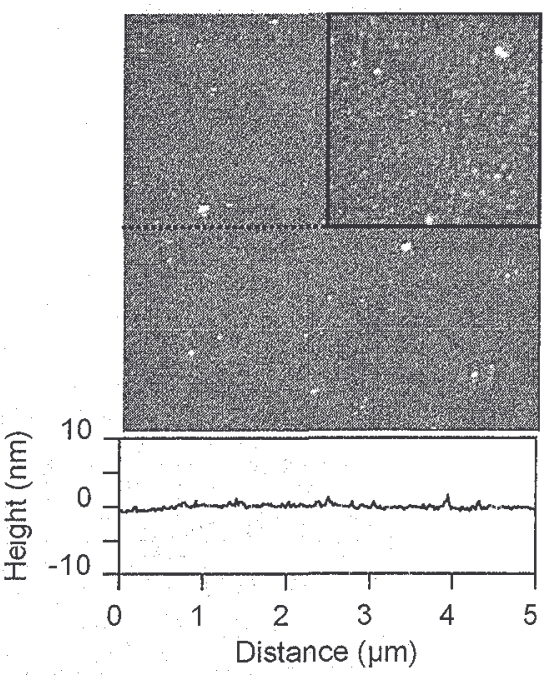

(a)

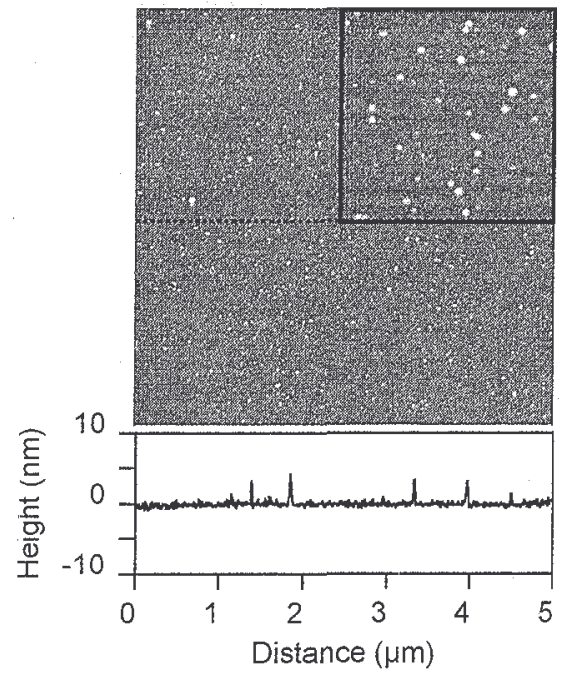

(c)

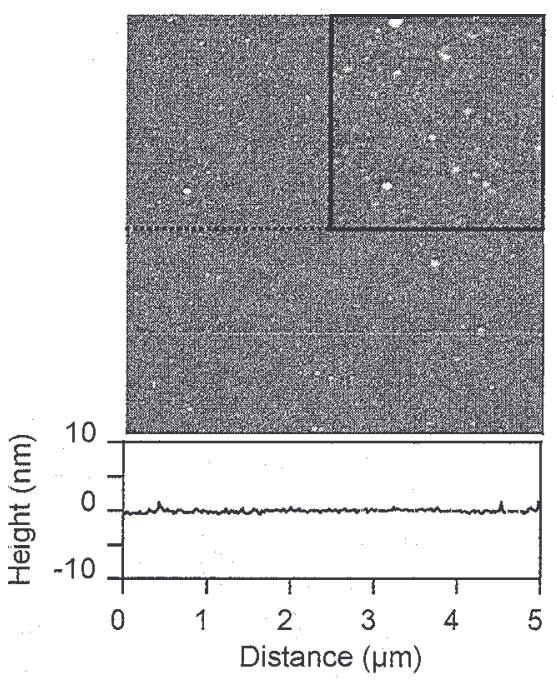

(b)

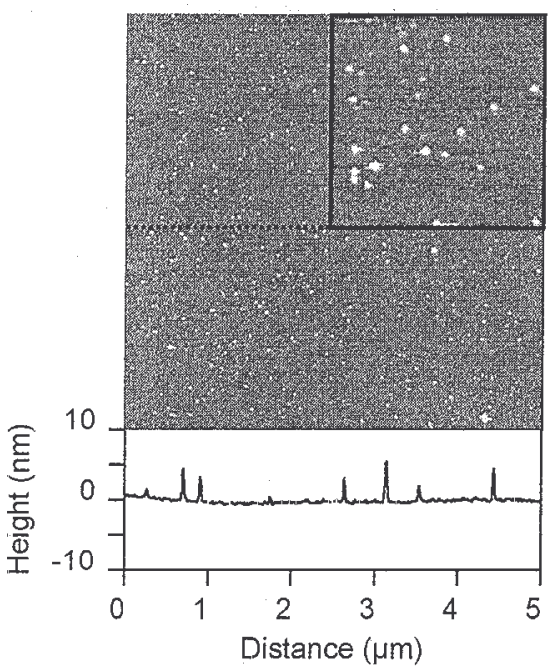

(d)

Fig. $2.5 \times 5 \mu \mathrm{m}$ AFM images (insert: $1 \times 1 \mu \mathrm{m}$ area) of SiOH substrata after adsorption of PtBUMA-bPDMAEMA from a $001 \mathrm{wt} \%$ solution $(a, b)$ and $a . . \quad 1 \mathrm{wt} \%$ solution $(c, d)$ Drying was performed by slow evaporation $(a, c)$ or quickly with a nitrogen flow $(b, d)$ Vertical scale: $10 \mathrm{~nm}$ for the $5 \times 5 \mu \mathrm{m}$ images, $5 \mathrm{~nm}$ for the inserts. Sections were taken at the places indicated by the dotted lines.

The difference of baseline height between scraped and unscraped zones was hardly noticeable.. On $\mathrm{SiCH}_{3}$ at a concentration of $001 \mathrm{wt} \%$ (Figs $3 \mathrm{a}$ and $3 \mathrm{~b}$ ), the morphology of the adsorbed layer was similar to that observed on $\mathrm{SiOH}$ in the same conditions.. At concentrations of $1 \mathrm{wt} \%$ (Fig. 3c) and $0.05 \mathrm{wt} \%$ (images not presented), for the slowly dried samples, islands of about 1.5-2 $\mu \mathrm{m}$ were observed The island height was up to about $50 \mathrm{~nm}$, as seen on the section. The high-resolution $0.5 \times 0.5$ $\mu \mathrm{m}$ insert, taken at the border of the island, recalls structures similar to micelles presented in Fig. 1, On fast-dried samples (Fig. 3d), the width of the islands was lower and highly variable; their height was about $50 \mathrm{~nm}$. The high resolution insert did not reveal the red blood cell morphology observed on slowly dried samples. Scraping the samples obtained below and above the CMC (Figs. 4b and 4d) displaced dot-like features and islands; the difference of baseline height between the scraped and the unscraped zones was clear, as seen on the sections shown with the images, and had a value of $1.8 \pm 0.5$ nm.

No difference of shape was observed between the $\mathrm{C}_{1 \mathrm{~S}}$ peaks recorded at the beginning and at the end of the XPS analysis. The $C_{1 \mathrm{~s}}$ peak intensity decreased by about $10 \%$ between the first and the second record, both in the presence or in the absence of adsorbed copolymer. This indicates that there is no marked depolymeiization of the copolymer during XPS analysis. 


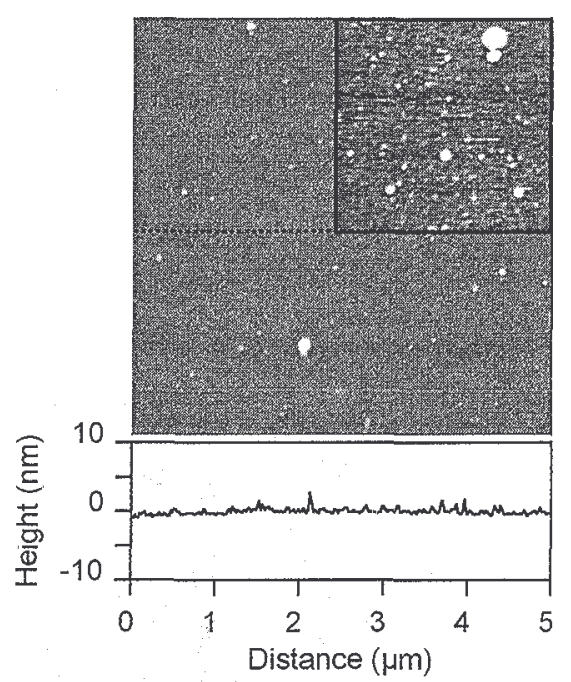

(a)

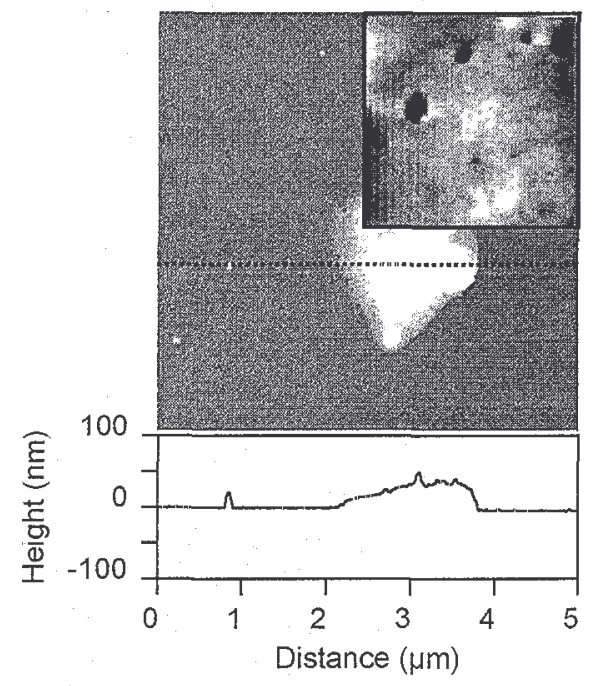

(c)

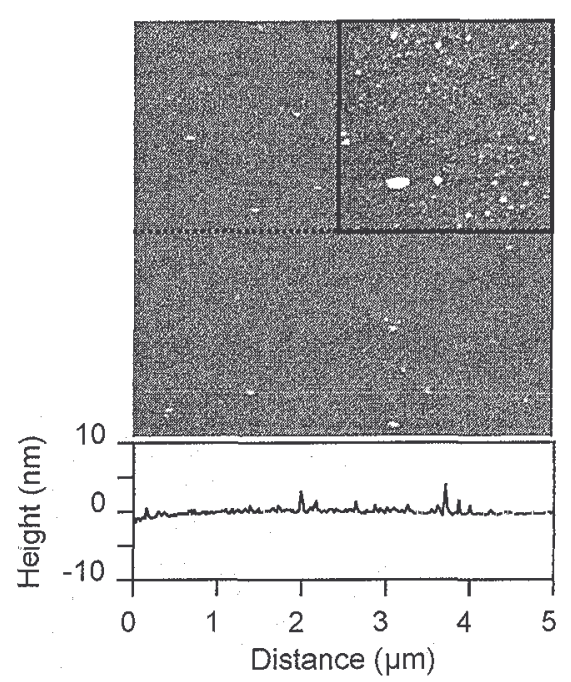

(b)

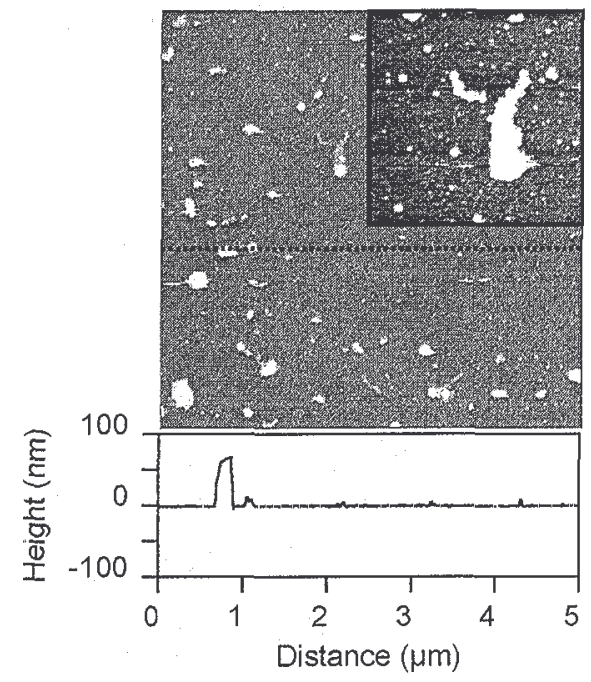

(d)

Fig $35 \times 5 \mu \mathrm{m}$ AFM images (insert: $1 \times 1$ m except for (c) $05 \times 05 \mu \mathrm{m}$ ) of $\mathrm{SiCH}_{3}$ substrata after adsorption of PtBUMA-b-PDMAEMA from a $0.01 \mathrm{wt} \%$ solution $(a, b)$ and a 1 wt\% solution $(c, d)$ Drying was performed by slow evaporation $(a, c)$ or quickly with a nitrogen flow $(b, d)$ Vertical scale: $30 \mathrm{~nm}$ for the $5 \times 5 \mu \mathrm{m}$ images, $5 \mathrm{~nm}$ for the inserts. Sections were taken at the places indicated by the dotted lines.

The $\mathrm{N}_{1 \mathrm{~s}}$ peak, as well as the evolution of the shape and intensity of the carbon peak, revealed the adsorption of the copolymer. The signal-to-noise ratio of the nitrogen peak was not lower than 5 . The nitrogen peak presented two components: one at $400.2 \mathrm{eV}$, related to unpiotonated nitrogen, and the other at $402.1 \mathrm{eV}$, related to protonated nitrogen The increase of the nitrogen signal with the concentration was stronger for the 400.2-eV component than for the 402.1-eV component. The latter was found on $\mathrm{SiCH}_{3}$ as well as on $\mathrm{SiOH}$; it may be due to coadsorption of water and proton transfer from the latter to the tertiary amine.

Further information was extracted from the carbon peak. The latter showed two distinct maxima (284.8 $\mathrm{eV}$ : carbon only bound to carbon and hydrogen; $288.6 \mathrm{eV}$ : carbon of ester, $\mathrm{CO}=\mathrm{O}$ ) and a shoulder near $286.7 \mathrm{eV}$ (carbon singly bound to nitrogen or oxygen) The proportion of the $\mathrm{CO}=\mathrm{O}$ component was measured by curve fitting without any constraints; therefore three components were considered, starting with the initial binding energies given above and an initial full width at half maximum of 141 $\mathrm{eV}$.

The N/Si, $(\mathrm{CO}=\mathrm{O}) / \mathrm{Si}$, and N/C molar ratios measured by XPS on two set of samples prepared independently are presented in Fig. 5 Considering the limited precision, the $\mathrm{N} / \mathrm{Si}$ and $(\mathrm{CO}=\mathrm{O}) / \mathrm{Si}$ ratios were in satisfactory agreement with the expected $\mathrm{CO}=\mathrm{O} / \mathrm{N}$ ratio of 2.7. More important, they were consistently higher on $\mathrm{SiOH}$ than on $\mathrm{SiCH}_{3}$, and were slightly higher at $1 \mathrm{wt} \%$ than at lower copolymer 
concentrations in the solution. No influence of the drying method was noticed. The N/C ratios for $\mathrm{SiCH}_{3}$ were close to the N/C ratio expected from the stoichiometry of the copolymer $(\mathrm{N} / \mathrm{C}=0,046)$, indicated on the graph by the dotted line. For $\mathrm{SiOH}$, the N/C ratios were more scattered than the N/Si and $(\mathrm{CO}=\mathrm{O}) / \mathrm{Si}$ ratios.

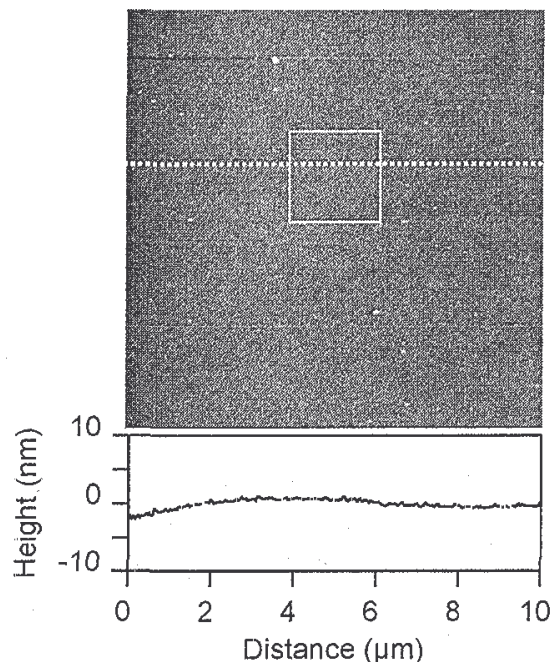

(a)

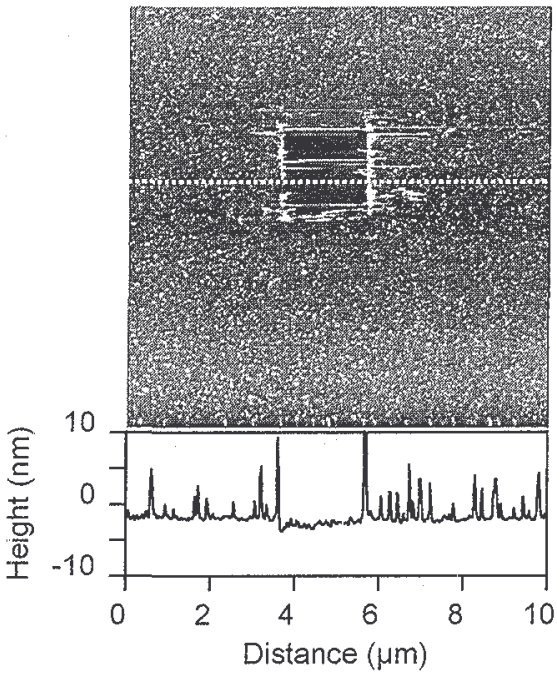

(c)

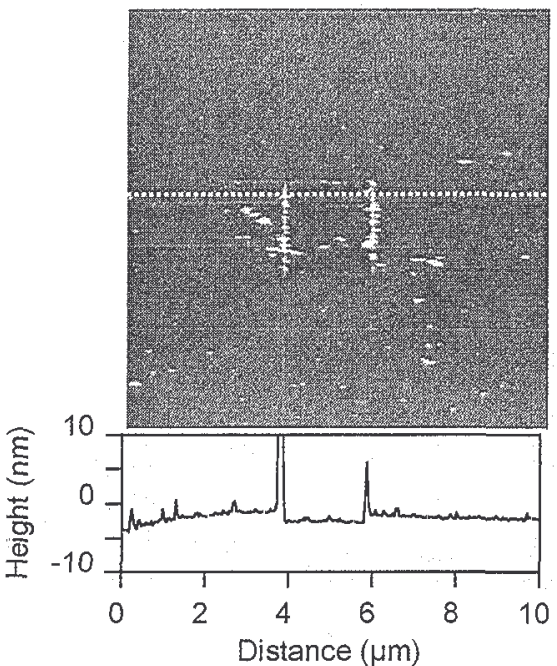

(b)

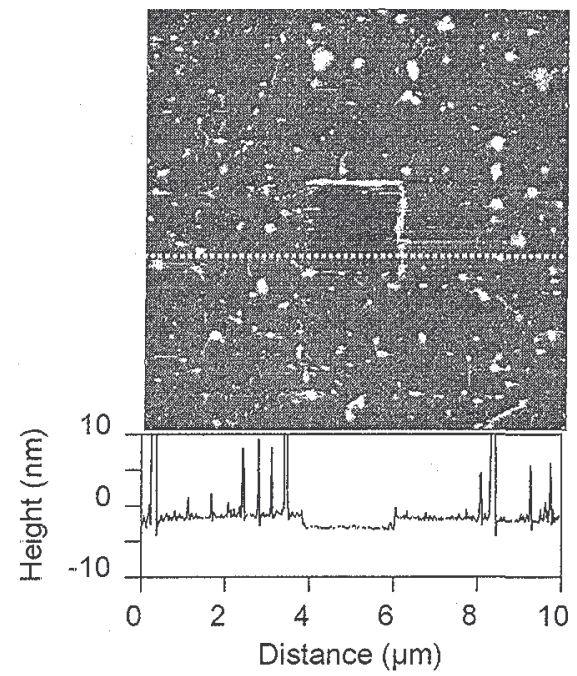

(d)

Fig $410 \times 10$ mm images of $\mathrm{SiOH}(a, c)$ and $\mathrm{SiCH}_{3}(b, d)$ substrata aftei adsorption of PtBUMA-bPDMAEMA from a $001 \mathrm{wt} \%$ solution $(a, b)$ and a $1 \mathrm{wt} \%$ solution $(c, d)$ and subsequent quick drying with a nitrogen flow The $2 \times 2 \mu \mathrm{m}$ central area was first scanned five times at a loading force of $8 \mathrm{nN}$ at $10 \mathrm{~Hz}$ Sections were taken at the places indicated by the dotted lines.

The N/Si molar ratio obtained from XPS analysis of samples prepared by adsorption was computed using a model in which the adsorbed layer is considered to have a homogeneous chemical composition, a degree of surface coverage $(\gamma)$, and a constant layer thickness (if) in the covered zones ( $t=$ cumulated thickness of adsorbate, neglecting voids),

$$
\begin{aligned}
& \frac{\mathrm{N}}{\mathrm{Si}}=\frac{i_{\mathrm{Si}}}{i_{\mathrm{N}}} \frac{\sigma_{\mathrm{N}}}{\sigma_{\mathrm{Si}}}\left(\gamma \lambda_{\mathrm{N}}^{\mathrm{copo}} C_{\mathrm{N}}^{\mathrm{copo}}\left[1-\left(\exp -t / \lambda_{\mathrm{N}}^{\mathrm{copo}} \cos \theta\right)\right]\right) \\
& \times\left(\gamma \lambda_{\mathrm{Si}}^{\text {subs }} C_{\mathrm{Si}}^{\mathrm{subs}} \exp \left(-t / \lambda_{\mathrm{Si}}^{\mathrm{cop} o} \cos \theta\right)\right. \\
& \left.\quad+(1-\gamma) \lambda_{\mathrm{Si}}^{\mathrm{subs}} C_{\mathrm{Si}}^{\mathrm{subs}}\right)^{-1},
\end{aligned}
$$

where $\mathrm{C}^{\text {copo }}$ is the concentration of nitrogen $\left(2.37 \mathrm{mmol} / \mathrm{cm}^{3}\right)$ in the copolymer and $\mathrm{C}_{\mathrm{Si}}{ }^{\text {subs }}$ is the 
concentration of silicon $\left(60 \mathrm{mmol} / \mathrm{cm}^{3}\right)$ in the substrate. The value of $60 \mathrm{mmol} / \mathrm{cm}^{3}$ was used, assuming that $2 / 3$ of the substrate contributing to the XPS spectrum was silicon and $1 / 3$ was silicon dioxide, as shown by the shape of the silicon peak In the case of $\mathrm{SiCH}_{3}$, the signal of silicon bound to carbon was neglected. $\lambda_{\mathrm{N}}{ }^{\text {copo }}, \lambda_{\mathrm{Si}}{ }^{\text {subs }}$, and $\lambda_{\mathrm{Si}}{ }^{\text {copo }}$ are the inelastic mean free paths of nitrogen photoelectrons in the copolymer $(3 . .30 \mathrm{~nm})$ and of silicon photoelectrons in the substrate $(3.17 \mathrm{~nm})$ and in the copolymer $(4.02 \mathrm{~nm})$, respectively.

They were calculated from Tanuma et al, [13], assuming that the density of the copolymer is $1 \mathrm{~g} / \mathrm{cm}^{3}$ and the energy gap is $5 \mathrm{eV}$; the value taken foi $\lambda_{\mathrm{Si}}{ }^{\text {subs }}$ was the election mean free path of Si in silicon. This equation provides, for each sample, an infinite set of $(\gamma-t)$ pairs compatible with the experimental $\mathrm{N} / \mathrm{Si}$ ratio The results obtained for concentrations of 0.01 and $1 \mathrm{wt} \%$ are presented in Fig, 6 as $\gamma$ vs $t$ plots, where each curve is deduced from an N/Si ratio which is the mean of the two experimental values given in Fig, 5a. It appears that the experimental N/Si ratios were compatible only with a surface coverage higher than $50 \%$. For a surface coverage of $100 \%$, the thickness of the adsorbed layer would be in the range of $1.5-3.5 \mathrm{~nm}$.
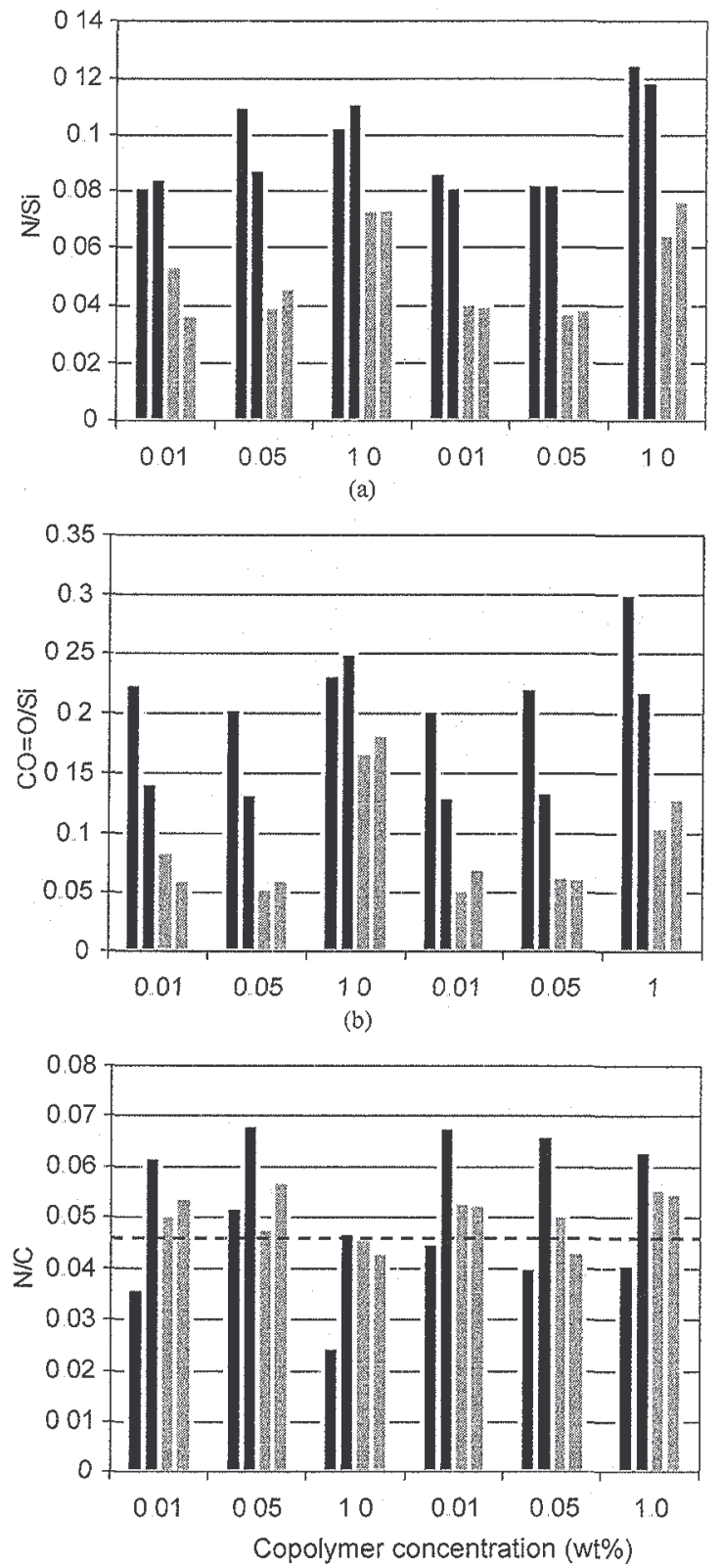

(c)

Fig $5 \mathrm{~N} / \mathrm{Si}$ (a), $\mathrm{CO}=\mathrm{O} / \mathrm{Si}$ (b) and N/C latios (c) measured by XPS on samples obtained aftei adsoiption of PtBUMA-b-PDMAEMA from a 0.01, 0.05, and $1 \mathrm{wt} \%$ solution and slow (left hand side of the giaph) or fast drying (right hand side of the graph) Black bar: SiOH substratum; grey bar: $\mathrm{SiCH}_{3}$ substratum For each sample, the two experimental values are presented. The interrupted line drawn on the N/C 


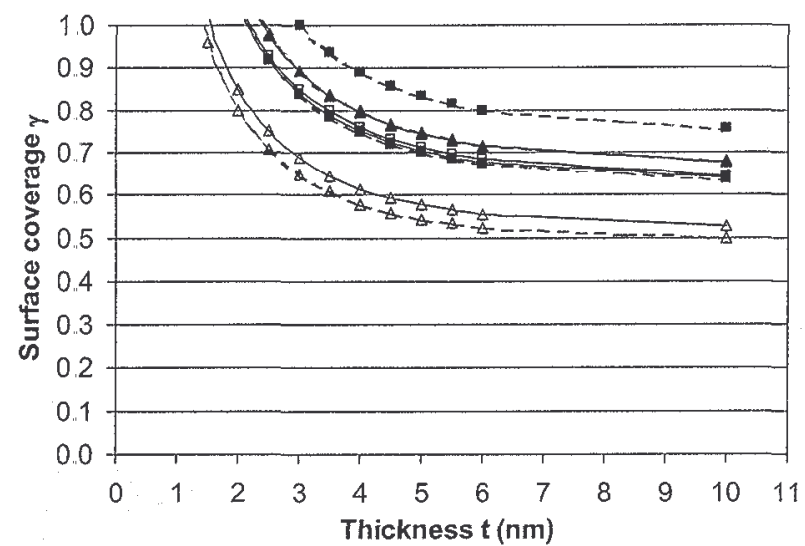

Fig. 6. Plot of surface coverage $\gamma v$ s thickness $t$, showing the pairs of values compatible with the N/Si ratio measured by XPS after adsorption of PtBUMA-b-PDMAEMA. Ihe experimental N/Si ratios used are the means of the two experimental values presented in Fig 5a. Squares: 1 wt\%; triangles: 001 wt\%; closed symbols: $\mathrm{SiOH}$; open symbols: $\mathrm{SiCH}_{3}$; continuous line: drying under ambient atmosphere; interrupted line: drying with a nitrogen flow.

\section{Discussion}

The lower water contact angle of freshly prepared $\mathrm{SiOH}$ and the higher value obtained after XPS analysis indicate that the samples submitted to adsorption were not strongly contaminated. With the data available here, it is not possible to determine whether the adventitious contamination took place in the spectrometer or during sample handling in air The larger variation of N/C ratios compared to N/Si ratios shown for $\mathrm{SiOH}$ in Fig. 5 may also be attributed to contamination, $\mathrm{SiCH}_{3}$, which possesses a lower surface energy, is less subject to contamination.

The deposited micelles imaged by AFM in air (Fig. 1) present a red blood cell shape This particular morphology could be explained by a tip indentation [14], the decreased contact area at the center of a micelle compared to the junction between two micelles increasing the deformation at the center However, since the samples are observed in the dried state at the minimum force value allowing contact between the tip and the sample, tip indentation should be very limited, Alternatively, the observed morphology may represent the real morphology obtained after drying, as discussed below. The radius of the deposited micelles, measured by AFM in aii (Fig. 1), is about half the hydrodynamic radius measured in toluene solution by light scattering. The size measured by AFM is not expected to be appreciably altered by the tip convolution, as the particles are closely packed. If the PDMAEMA core remains spherical during sample preparation for TEM examination, its diameter measured by this method $(8 \mathrm{~nm})$ corresponds to a volume of about $268 \mathrm{~nm}^{3} /$ micelle and a degree of association of 16 molecules/micelle Accordingly, the volume of compact PtBUMA would be about $456 \mathrm{~nm}^{3} / \mathrm{micell}$. If the PtBUMA corona of deposited micelles was forming a flat and compact rim of external radius 21 $\mathrm{nm}$, as measured by AFM, around a PDMAEMA core of radius 4 or $6.5 \mathrm{~nm}$, as evaluated by TEM and AFM, respectively, the rim thickness would be about $0.35 \mathrm{~nm}$. This is in contradiction to the AFM images and indicates that PtBUMA does not shrink into a compact state upon drying, but remains in extended conformation This supports the idea that the observed micelle morphology is due to the presence of a dense PDMAEMA core embedded in a non compact rim material. Note that a dense core PDMAEMA core with a collapsed rim material would give a fried egg shape.

When the samples are rinsed after immersion, the XPS results are compatible with degrees of surface coverage, which are in the range of 1-0.5, and with thicknesses, which are in the range of 1.5-6 nm (Fig. 6) Accordingly, the islands (Figs. 3c, 3d) and the dot-like features (Figs. 2, 3a, 3b) may not account for the XPS data. This indicates the presence of a more or less continuous adsorbed layer and is found whatever the substrate, the copolymer concentration, and the drying mode It is not compatible with the retention of micelles which simply shrink upon drying. It is thus concluded that individual copolymer molecules adsorb. This is supported by the similarities between results obtained using copolymer concentrations which vary in a range of two orders of magnitude including the CMC. It is also supported by the images obtained after scraping on $\mathrm{SiCH}_{3}$ (Figs. 4c, 4d).

The two substrates differ by the fact that scraping does not affect significantly the layer adsorbed on 
$\mathrm{SiOH}$ and that the N/Si ratios are about twice higher on $\mathrm{SiOH}$ compared to $\mathrm{SiCH}_{3}$ (Fig. 5). This can be explained by a higher affinity of the copolymer for $\mathrm{SiOH}$ than for $\mathrm{SiCH}_{3} \mathrm{On} \mathrm{SiOH}$, copolymer molecules would adsorb via the PDMAEMA block thanks to hydrogen bonding, explaining why the adsorbed layer is more resistant to scraping. Such behavior has already been reported for the polystyrene-b-polyvinylpyridine (PS- $b$-PVP) copolymer adsorbed on mica or on an octadecyltrichlorosiloxane self-assembled monolayer [7]. The lower reproducibility of N/C ratios (Fig. 5) and of $\mathrm{C} / \mathrm{Si}$ ratios (not shown) after adsorption on $\mathrm{SiOH}$ compared to $\mathrm{SiCH}_{3}$ is attributed to the greater tendency of the former to adsorb adventitious contamination.

The dot-like features observed on $\mathrm{SiOH}$ above the CMC (Figs. 2c and 2d) are randomly scattered and are thus not displaced by drying, whether quick or slow. As their height isabout $5 \mathrm{~nm}$, their apparent width of $29 \pm 5 \mathrm{~nm}$ could possibly be due to AFM convolution.

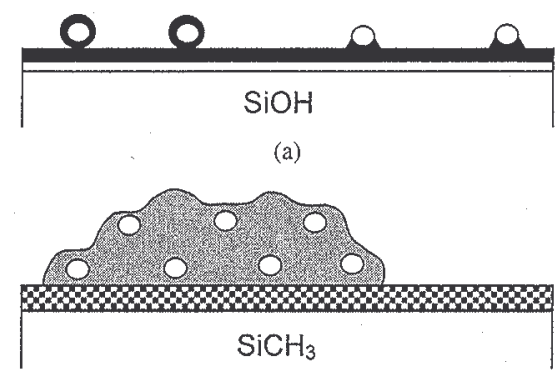

(b)

Fig 7, Schematic representation of the copolymer layer adsorbed and dried on $\mathrm{SiOH}$ (a) and on $\mathrm{SiCH}_{3}$ (b). White: PDMAEMA; black: PtBUMA; gray: loosely packed PtBUMA

A spherical particle with a diameter $d$ of $5 \mathrm{~nm}$, revealed by a tip with a radius of curvature $R$ of $20 \mathrm{~nm}$, would have an apparent size along the surface plane equal to $W=(d 2 R)^{0.5}=28 \mathrm{~nm}[15]$. A particle of radius about $5 \mathrm{~nm}$ is compatible with a compact dried micelle Thus the dot-like features could be micelles sitting on a layer of adsorbed copolymer molecules. This does not exclude the PtBUMA rim associating with the adsorbed copolymer layer, which would tend to expose the PDMAEMA core to the air as proposed by Webber et al. [12] and Meiners et al. [16] for other micelle systems. The absence of aggregation of the micelles upon drying may indeed be due to anchorage of the micelles in the adsorbed copolymer layer through entanglement of PtBUMA blocks as sketched in Fig. 7a.

The islands observed on $\mathrm{SiCH}_{3}$ above the $\mathrm{CMC}$ are thought to be made by the association of micelles upon drying. This is supported by the high-resolution images taken at the border of the islands after slow drying (Fig. 3c), which present features with size and shape similar to those for deposited micelles (Fig. 1). The decrease of the lateral size of the aggregates as the drying rate increases is in accordance with the expected result of the competition between solvent evaporation and micelle displacement at the solvent-air interface The occurrence of aggregation on the $\mathrm{SiCH}_{3}$ substrate, in contrast with $\mathrm{SiOH}$, may be due to the fact that micelles are not so tightly anchored in the adsorbed copolymer layer due to the occurrence of PDMAEMA blocks in the outer part of the adsorbed layer as sketched in Fig. 7b. It appears that the micelles dried in the aggregated form on $\mathrm{SiCHj}$ show an extended PtBUMA rim, while isolated micelles dried on $\mathrm{SiOH}$ have a compact rim

The surface concentration of micelles found on both substrates above the CMC is expected to be strongly dependent on the rinsing procedure The dot-like features observed below the $\mathrm{CMC}$, both on $\mathrm{SiOH}$ (Figs. 2a and 2b) and on $\mathrm{SiCH}_{3}$ (Figs. 3a and 3b), are scarce and unevenly distributed; their size also varies appreciably. They may be micelles or undefined aggregates formed by deposition of copolymers present in the film of solvent left after rinsing.

\section{Conclusion}

The adsorption of the PtBUMA-b-PDMAEMA block copolymei onto silicon ( $\mathrm{SiOH})$ and $\mathrm{CH}_{3}$-grafted silicon $\left(\mathrm{SiCH}_{3}\right)$ surfaces leads to the rapid formation of a layer of individual copolymer molecules, 1.5$3 \mathrm{~nm}$ thick, in the dried state. This occurs over a wide range of copolymer concentrations above and below the CMC.

Above the $\mathrm{CMC}$, on $\mathrm{SiOH}$, dot-like features are randomly scattered on the adsorbed layer. They have a narrow size distribution (height about $5 \mathrm{~nm}$ ) and may be individual micelles. On $\mathrm{SiCH}_{3}$, the particles found on top of the adsorbed layer are 50-nm-high micelle aggregates, the lateral size of which is 
strongly influenced by drying conditions. The differences between $\mathrm{SiOH}$ and $\mathrm{SiCH}_{3}$ (adsorbed amount, resistance of the first adsorbed layer to scraping, behavior of micelles retained above the CMC) are attributed to a stronger adsorbate-substrate interaction on $\mathrm{SiOH}$, via hydrogen bonding of the PDMAEMA block, leading to the orientation of the PtBUMA block toward the solution Micelles deposited on $\mathrm{SiOH}$ by immersion above the $\mathrm{CMC}$ and no rinsing show a red blood cell shape which is due to the incomplete shrinking of the PtBUMA rim upon drying. Micelles present on $\mathrm{SiOH}$, either by adsorption above the CMC or by deposition, could be exploited to provide surfaces with chemical heterogeneities at the nanometer scale. Indeed, when exposed to water, the PDMAEMA core could swell and crop out of a background made of PtBUMA chains.

\section{Acknowledgments}

The authors thank late Professor P, Grange for the use of the AFM. The support of the Foundation for Training in Industrial and Agricultural Research (FRIA), the National Foundation for Scientific Research (FNRS), the Federal Office for Scientific, Technical and Cultural Affairs (Interuni-versity Poles of Attraction Program), and the Research Department of the Communaute Francaise de Belgique (Concerted Research Action) is gratefully acknowledged.

\section{References}

[1] K. Emoto, Y Nagasaki, K Kataoka, Langmuir 15 (1999) 5212-5218

[2] N.-P Huang, G Csucs,K Emoto, Y. Nagasaki, K Kataoka, M Textoi, D, Spencer, Langmuir 18 (2002) 252-258

[3] H Otsuka, Y Nagasaki, K Kataoka, Curr. Opin. Colloid Interface Sci 6 (2001) 3-10.

[4] IP. Spatz, T Herzog, S. Mobmer, P Ziemann, M Moller, Adv Mater 11 (2) (1999) 149-153.

[5] IP Spatz, S. Mossmer, C. Hattmann, M. Moller, T Herzog, M Krieger, H -G. Boyen, P Ziemann, Langmuit 16 (2000) 407-415

[6] M Regenbrecht, S Akari, S Forster, H. Möhwald, I. Phys Chem. 103 (1999)6669-6675

[7] J.C Meiners, A. Ritzi, M.H. Rafailovitch, I Mlynek, G Ktausch, Appl Phys A 61 (1995)519-524,

[8] H. Walter, P Miiller-Buschbaum, J S Gutmann, C Lorentz-Haas, C. Harrats, R. Jerome, M Stamm, Langmuir 15 (1999) 6984-6990.

[9] S.E Webber, J Phys Chem. B 102 (1998) 2618-2626

[10] K Eskilsson, L M Grant, P. Hansson, F Tiberg, Langmuir 15 (1999) 5150-5157

[11] VM De Cupere, S Biltresse, I Marchand-Brynaert, PG Rouxhet, J Colloid Interface Sci, in press

[12] G.B. Webber, EI Wanless, S P Armes, F.L.. Baines, S Biggs, Langmuir 17(2001)5551-5561

[13] S. Ianuma, C.I Powell, DR Penn, Surf Intel face Anal 25 (1997) 25-31

[14] I P. Spatz, S Sheiko, M Moller, Langmuir 13(1997)4699-4703.

[15] I. Fang, CM. Knobler, M Gingery, FA Eiserling, I. Phys Chem B 101(1997)8692-8703

[16] I.C. Meiners, H Elbs, A Ritzi, J. Mlyneck, G Krausch, I. Appl Phys 80(4)(1996)2224-2227 